Check for updates

Cite this: RSC Adv., 2018, 8, 16781

\title{
Designable core-shell graphite particles for thermally conductive and electrically insulating polymer composites $\uparrow$
}

\author{
Takashi Hirahara (iD *
}

Electrically insulating graphite particles were prepared by coating graphite with electrically insulating materials via a two-step mechanical mixing process. Graphite particles were treated with a binder in the $1^{\text {st }}$ mixing process and coated with an electrically insulating particle in the $2^{\text {nd }}$ mixing process under high shear forces within a short processing time (below $1 \mathrm{~min}$ ). Micron-sized graphite particles were successfully coated with various inorganic particles of appropriate particle diameter. Talc and boron nitride exhibited good affinities with graphite and formed effective coating layers to render reliable electrical insulation. Graphite coated with talc and boron nitride exhibited a high volume resistivity, greater than $10^{9} \Omega \mathrm{cm}$. The insulating property was retained even after compounding and moulding the coated graphite particles with a polymer. The two-step coating process under high shear forces is a promising method for production of coated graphite particles.

Received 5th March 2018 Accepted 17th April 2018

DOI: $10.1039 / \mathrm{c} 8 \mathrm{ra0} 01946 \mathrm{k}$

rsc.li/rsc-advances fillers for efficient heat conduction is limited to conventional fillers such as aluminium oxide $\left(\mathrm{Al}_{2} \mathrm{O}_{3}\right)$, magnesium oxide ( $\mathrm{MgO})$, and boron nitride (BN). ${ }^{\mathbf{1 4 - 1 6}}$ Therefore, it is difficult to obtain good composite performance by material design. $\mathrm{BN}$ is a well-known conventional filler that can provide EI; however, it shows a moderate TC of approximately $60 \mathrm{~W} \mathrm{~m}^{-1} \mathrm{~K}^{-1}$ and has disadvantages of high cost and compounding difficulty at high contents. ${ }^{17}$ Alternative materials such as aluminium nitride (AlN) and beryllium oxide (BeO) exhibit both high TC and good EI, but, they are disadvantageous because of the hygroscopic nature of the former and the hazardous property of the latter. ${ }^{18,19}$ On the other hand, graphite particles (GRPs) exhibit a relatively high TC $\left(>100 \mathrm{~W} \mathrm{~m}{ }^{-1} \mathrm{~K}^{-1}\right)$. Especially, micron-sized GRP is clearly safe and economical compared with nano-sized material such as graphene and graphite nano platelets. ${ }^{20,21}$ However, the modification is required to use GRP as electrically insulating filler because of the electrical conductivity. ${ }^{22}$ Thus, a new design is required to increase both the TC and the EI properties of the filler and the polymer composite.

There has been remarkable progress in the design of thermally conductive and electrically insulating fillers and its polymeric composites such as modified BN. ${ }^{23-25}$ These materials show excellent properties, while the process applicability still needs to be considered for practical use. In the manufacturing perspective, one promising approach is to deposit an electrically insulating coating on the surface of GRPs; this method is advantageous from the view point of not only performance but also process cost. However, a coating layer usually prevents direct contact between the GRPs, resulting in a slight decrease in the TC. For selecting coating materials without limitation, thermally conductive paths can be formed by controlling the
DuPont Kabushiki Kaisha, Transportation \& Advanced Polymers, 19-2 Kiyohara Kogyodanchi, Utsunomiya-shi, Tochigi 321-3231, Japan. E-mail: takashi.hirahara@ dupont.com

$\dagger$ Electronic supplementary information (ESI) available. See DOI: 10.1039/c8ra01946k 
coating morphology. Furthermore, process-related and economic issues can be solved using this concept. This freedom of coating design is important to realise the concept of electrically insulating GRPs for practical applications.

Several methods have been adopted to obtain electrically insulating GRPs with high volume resistivity and high TC. ${ }^{26-28}$ For instance, it has been reported that chemically deposited silica coatings on GRPs show good volume resistivity; ${ }^{29-31}$ however, the application of this type of coated GRP (C-GRP) is limited to thermosetting resins because of the brittleness of the coating layer. The brittleness must be reduced to extend the applications of GRPs to thermoplastic resins in terms of manufacturing. Especially, thermally conductive thermoplastic resins for injection moulding is usually compounded with a large amount of filler to achieve a high TC. The filler is subject to high shear forces during melt extrusion processes; thus, the coating layer is likely to be broken, depending on the filler content and the adhesion between the fillers and the coating layers. ${ }^{32}$ This tendency becomes stronger for large-sized GRPs. A thicker coating layer is one of the solutions to reduce brittleness. However, the TC of the coated filler will decrease if the TC of the coating layer is low. Therefore, the silica coating method cannot balance the brittleness and the TC performance, because the coating layer is limited to silica produced by specific chemical methods. A coating layer consisting of other inorganic particles is preferred to overcome the brittleness and balance the TC and the EI.

In this study, we adopted the mechanical mixing method to obtain electrically insulating GRPs for melt extrusion and injection moulding. The mechanical mixing method can overcome the limitation of coating material selection; therefore, it is possible to obtain higher TC and volume resistivity of the coated filler and the polymer composite. We used mechanofusion as the coating process owing to its advantages of (1) effective highspeed mixing, (2) short operating time, and (3) high-shearing condition. Especially, a high-shear condition forces the filler to be stiff; hence, it can endure the shearing condition during compounding with a polymer. The mechanofusion method has been studied for many years for the preparation of unique fillers in the particle technology field. ${ }^{33-35}$ This method can be used to prepare a wide range of hybrid fillers with unique morphologies, such as coated fillers, embedded fillers, and combined fillers. Generally, the morphology of a filler can be controlled by the particle size and the operating condition. It is necessary to select relatively large GRPs to achieve high TC values; but larger GRPs tend to be more brittle than smaller ones. This trade-off relation is a bottleneck to obtain practically applicable C-GRP. In the novel study, we carried out mechanically multiple-step processes to meet the EI requirement of designable core-shell GRPs for injection mouldable polymer composites.

\section{Experimental}

\section{Materials and methods}

Materials for GRP modification. A submicron-sized GRP X100 (D50: $136 \mu \mathrm{m}$ ) was supplied by Ito Graphite Co. An aqueous solution binder was prepared by dissolving methylol melamine S-176 (Nippon Carbide Industries Co.) in pure water (concentration: $0.42 \mathrm{~g} \mathrm{~mL}^{-1}$ ). Two types of talc, viz. HTP Ultra 5 (D50: $0.6 \mu \mathrm{m})$, HTP 2C (D50: $2 \mu \mathrm{m})$ were procured from IMI FABI L.L.C. Three types of BN, namely SP-3 (D50: $4 \mu \mathrm{m}$ ), GP (D50: $8 \mu \mathrm{m}$ ), and SGP (D50: $18 \mu \mathrm{m}$ ) were supplied by Denka Co. Two types of mineral particles, sericite (D50: $2 \mu \mathrm{m}$ ) and mica (D50: $5 \mu \mathrm{m}$ ), were supplied by Kinsei Matec Co. and Yamaguchi Mica Co., respectively. Boemite BMF (D50: $3 \mu \mathrm{m}$ ), titanium dioxide Ti-pure R108 (D50: $0.23 \mu \mathrm{m}$ ), and calcium difluoride HO-\#100 (D50: $6 \mu \mathrm{m}$ ) were supplied by Kawai Lime Industry Co., DuPont, and Sankyo Seifun Co., respectively.

Materials for polymer composite. An in-house prepared polybutylene terephthalate resin (PBT) was used for melt extrusion of each C-GRP.

Mechanofusion method for GRP modification. The mechanofusion process was carried out using a Nobilta NOB-130 equipment manufactured by Hosokawa Micron Co. under a nitrogen atmosphere. The GRPs, aqueous binder, and coating particles were introduced into a cylinder equipped with a hopper, and then, mechanically mixed and sheared by rotary blades at a rotating speed of $3000 \mathrm{rpm}$. The clearance between the rotary blade and the sample jacket was fixed at $3 \mathrm{~mm}$. The operating temperature was controlled at $30^{\circ} \mathrm{C}$ by water cooling. The obtained modified GRPs were cured at $120{ }^{\circ} \mathrm{C}$ for $3 \mathrm{~h}$ to convert the binder to melamine resin.

Preparation of polymer/C-GRP composite. C-GRP was compounded with the PBT polymer using a twin screw batch extruder MC15 (DSM Xplore Co.) equipped with a mini injection machine. The melt extrusion was conducted at $275^{\circ} \mathrm{C}$ at a screw speed of $100 \mathrm{rpm}$ for $30 \mathrm{~s}$. The melting mixture was injected and moulded as a $16 \times 16 \times 1 \mathrm{~mm}^{3}$ plate for property evaluations. The content of C-GRP in the composites was fixed at $26 \mathrm{vol} \%$ in all the samples (Scheme 1).

\section{Characterisation}

Structural properties. The morphologies of the GRPs and the moulded plate were observed using a Miniscope TM-1000 scanning electron microscope (SEM; Hitachi Science Systems Co.). The specific gravity of the moulded plate was measured by the Archimedes method using a SD-200L gravimeter (Alfa Mirage Co.). Pure water was selected as the solvent to use the

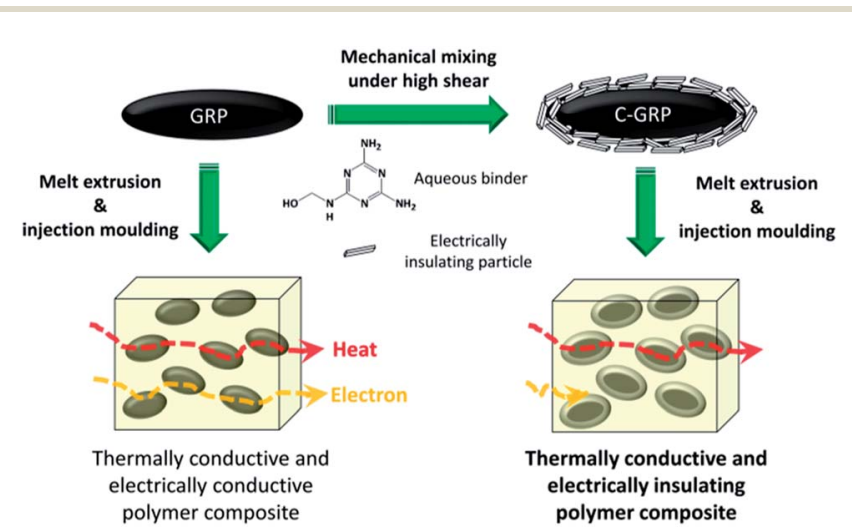

Scheme 1 Schematic of the fabrication concept of electrically insulating C-GRP and its application in injection moulding. 
value of specific gravity as bulk density $(\rho)$. The heat capacity $\left(C_{\mathrm{p}}\right)$ was measured by modulated differential scanning calorimetry at $23{ }^{\circ} \mathrm{C}$ using a Q2000 differential scanning calorimeter (TA instruments Co.). Sapphire was used as the reference to compare the heat capacity of each tested sample.

Volume resistivity measurement. The apparent volume resistivity of the compressed GRPs was measured using a FLUKE 1507 insulation tester (FLUKE Co.) along the compression direction. The target particles $(0.2 \mathrm{~g})$ were compressed using a $10 \mathrm{~mm}$ diameter cylinder under a pressure of $0.13 \mathrm{~N} \mathrm{~mm}^{-2}$. On the other hand, the volume resistivity of the polymer composite was measured using a Hiresta-UP (MITSUBISHI KAGAKU Co.) ohmmeter equipped with a $10 \mathrm{~mm}$ diameter UR-SS probe as an electrode at $23^{\circ} \mathrm{C}$. The measurement was conducted for injection moulded plates along the thickness direction in the voltage range of 100 to $1000 \mathrm{~V}$ at $30 \mathrm{~s}$ intervals.

Thermal conductivity measurements. The thermal diffusivity $(\alpha)$ of the moulded plate was measured by the laser flash method using a LFA447 nanoflash equipment (NETZSCH Co.) at $23{ }^{\circ} \mathrm{C}$. The measurement was conducted on a $16 \times 16 \times 1 \mathrm{~mm}^{3}$ plate along the in-plane direction which is the flow direction of injection moulding. All the samples were sprayed with a carbon ointment at the spot where laser was irradiated prior to the experiments. The heat diffusivity curve was analysed using an isotropic/heat loss model. The apparent thermal conductivity $(\lambda)$ was calculated using the following equation.

$$
\lambda\left(\mathrm{W} \mathrm{m}{ }^{-1} \mathrm{~K}^{-1}\right)=\alpha\left(\mathrm{mm}^{2} \mathrm{~s}^{-1}\right) \times C_{\mathrm{p}}\left(\mathrm{J} \mathrm{g}^{-1} \mathrm{~K}^{-1}\right) \times \rho\left(\mathrm{g} \mathrm{cm}^{-3}\right)
$$

\section{Results and discussion}

\section{Electrically insulating coating process for GRP}

The target morphology for EI is a uniform coating of particles on the surface of GRP. It has been reported that round shaped particles can be easily coated with other particles by mechanical processes. ${ }^{36}$ On the other hand, it is difficult to coat platy particles by mechanical mixing processes such as mechanofusion. The difficulty in coating depends on the coating material and its ratio in the target particle. The content of coating particles should be less to exploit the excellent TC performance of a core GRP. Therefore, in the present study, a small amount of liquid binder was used to obtain a liquid bridge force, because a simple dry mixing did not produce a uniform coating experimentally. We considered two systems to realise the coating morphologies: (i) GRP/binder and (ii) GRP/binder/ coating particle. In addition, we carried out two processes to clarify their effect on filler morphology and the corresponding volume resistivity: (a) facile one-step mixing process with all the constituents and (b) an effective two-step process comprising $1^{\text {st }}$ mixing of GRP/binder and $2^{\text {nd }}$ mixing of coating particle. Table 1 shows the compositions of the samples and the details of the high-shear mixing conditions. Three types of C-GRP were prepared, and their morphologies were studied after processing. We selected GRP X100 (D50: $136 \mu \mathrm{m}$ ) as a starting material to investigate the effect of coating process. The methylol
Table 1 Compositions of the different samples and their mixing conditions with NOB-130 system

\begin{tabular}{llll}
\hline & C-GRP 1 & C-GRP 2 & C-GRP 3 \\
\hline GRP/g (vol\%) & $70(91.3)$ & $70(72)$ & $70(72)$ \\
Methylol melamine/g (vol\%) & $4.2(8.7)$ & $4.2(7)$ & $4.2(7)$ \\
Talc/g (vol\%) & - & $25(21)$ & $25(21)$ \\
Rotating speed/rpm & 3000 & 3000 & 3000 \\
$1^{\text {st }}$ mixing time/min & 5 & - & 5 \\
$2^{\text {nd }}$ mixing time/min & - & 0.5 & 0.5
\end{tabular}

melamine aqueous solution was used as a binder for the GRP and the coating particles because of the good affinity of melamine moiety on the $\pi$ conjugation of the GRP surface. ${ }^{37}$ Prior to evaluation, the binder was converted to melamine resin after curing the obtained C-GRP. A submicron-sized mineral particle talc HTP Ultra 5 (D50: $0.6 \mu \mathrm{m})$ was used as the $1^{\text {st }}$ candidate particle as it has a large surface area for an effective coating. Samples C-GRP 1, C-GRP 2, and C-GRP 3 were prepared by the combination of processes (i)/(a), (ii)/(a), and (ii)/(b), respectively.

Fig. 1 shows the SEM images of raw GRP, C-GRP 1, C-GRP 2, and C-GRP 3. C-GRP 1 retained the platy morphology even after mixing, similar to that of raw GRP. C-GRP 2 also exhibited a platy morphology; however, the particle size was smaller than that of raw GRP. The reduced particle size of C-GRP 2 can be attributed to fragmentation of large GRPs by the mechanical shearing process. ${ }^{38}$ In Fig. 1(c), the grey regions represent GRP/ binder, whereas the white regions represent talc in C-GRP 2. The contrast is not uniform, which indicates that the talc particles are not coated uniformly. A possible reason is the intermixing of the talc particles and the GRP fragments, which limits the amount of talc on the surface coating. On the contrary, C-GRP 3 exhibited uniform white regions on the surface of each particle, which indicates that C-GRP 3 is well coated among all the samples with the similar average particle diameter to that of raw GRP (Fig. S1, ESI $\dagger$ ). To evaluate its shear resistance, C-GRP 3 was compounded with the PBT polymer using a twin screw extruder under an average shear rate of 33
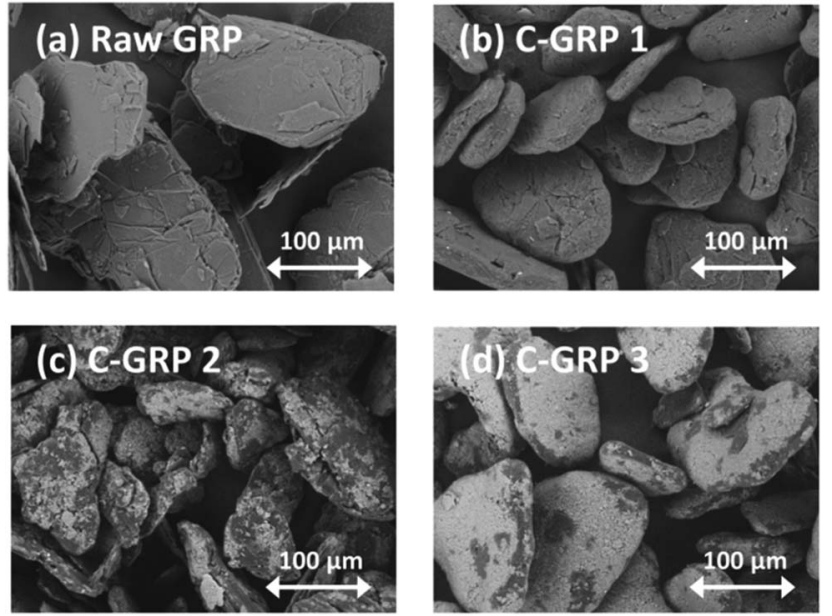

Fig. 1 SEM images of (a) raw GRP, (b) C-GRP 1, (c) C-GRP 2, and (d) CGRP 3 mixed by the high-shear mixing process. 

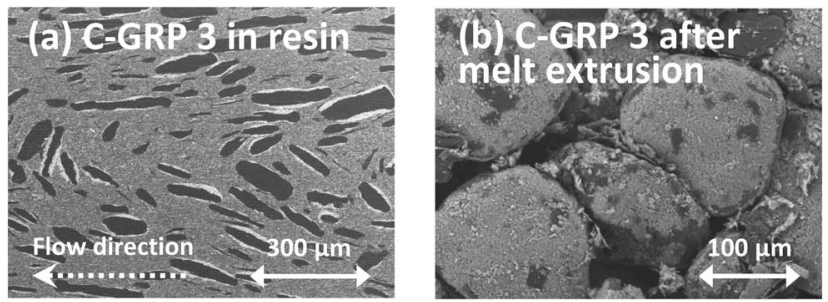

Fig. 2 Cross-sectional SEM images of the (a) moulded resin plate containing C-GRP 3 and (b) the C-GRP 3 morphology after the removal of resin moiety by curing at $500{ }^{\circ} \mathrm{C}$ for $1 \mathrm{~h}$ in air.

$\mathrm{s}^{-1}$ and moulded as a plate (C-GRP $3: 26 \mathrm{vol} \%$ ) by the injection process. Fig. 2(a) represents the cross-sectional images of the moulded plate of C-GRP 3. The talc coating layer is still observed as white regions around the GRP core represented by black regions. The fine talc particles possibly contribute to the high breakage energy of C-GRP 3, supported by breakage simulation of core-shell particles. ${ }^{39}$ For further confirmation of the morphology, the polymer moiety in the plate was removed by curing at $500{ }^{\circ} \mathrm{C}$ for $1 \mathrm{~h}$ in air. The morphology of C-GRP 3 is almost similar to that before the melt extrusion and the moulding processes. This fact indicates that C-GRP 3 has enough shear resistance to retain the coating layer during the melt extrusion process.

We evaluated the volume resistivity of each particle to clarify the coating effect. Fig. 3 shows the volume resistivity of raw GRP and the different C-GRP samples in the compressed particle form. The volume resistivity of C-GRP 1 increased from 6 to 15 $\Omega \mathrm{cm}$. This result suggests that the binder component contributes to EI on the surface of the GRP core. C-GRP 2 exhibited a volume resistivity of $10^{3} \Omega \mathrm{cm}$, which is hundred times higher than that of C-GRP 1. This improvement is attributed to the decrease in the content of GRP, from 91.3 vol\% in C-GRP 1 to $72 \mathrm{vol} \%$ in C-GRP 2 . The SEM image of C-GRP 2 indicates that the some talc particles are exposed to the surface of GRP, which is the morphologic effect on EI. The volume resistivity of C-GRP 3 was approximately $10^{9} \Omega \mathrm{cm}$. The SEM image of C-GRP 3 supports the notion that the coating layer plays an important role in preventing contact between the GRP cores. These results indicate that the two-step mechanical mixing process can be used to prepare well-coated particles with a high volume resistivity.

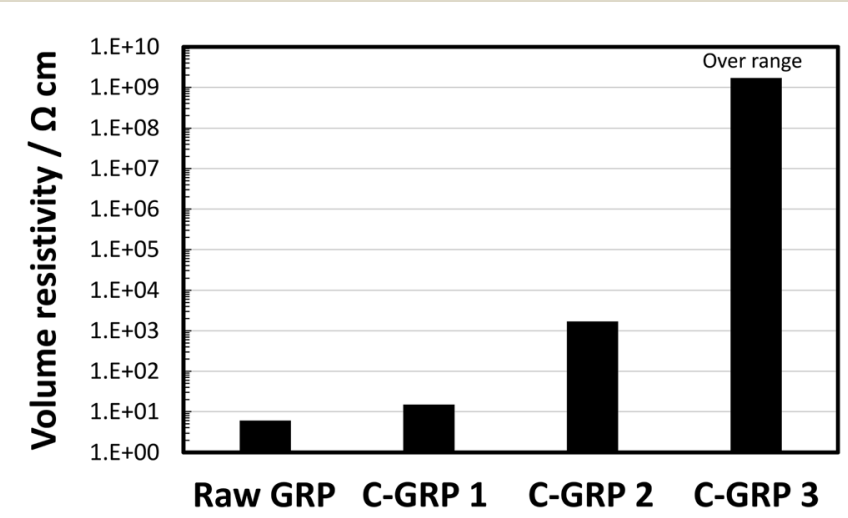

Fig. 3 Volume resistivity of raw GRP, C-GRP 1, C-GRP 2, and C-GRP 3 prepared by the mechanofusion process.
To clarify the effect of the composition of C-GRP on the volume resistivity, we varied the contents of the binder and the coating particle. The methylol melamine aqueous solution (concentration: $0.42 \mathrm{~g} \mathrm{~mL}^{-1}$ ) and talc HTP Ultra 5 (D50: $0.6 \mu \mathrm{m}$ ) particles were used as the binder and the coating particle, respectively. Fig. 4 shows the volume resistivity of C-GRP as a function of the talc content. At $4 \mathrm{vol} \%$ binder content, the volume resistivity is saturated at $8 \mathrm{vol} \%$ talc content, exhibiting a value of $10^{6} \Omega \mathrm{cm}$. On the other hand, the C-GRP containing $8 \mathrm{vol} \%$ binder exhibited a volume resistivity of approximately $10^{9} \Omega \mathrm{cm}$ at $12 \mathrm{vol} \%$ talc content. This result indicates that the high volume resistivity of C-GRP is related to not only the amount of talc but also the existence of the binder. Considering the effect of coating, the increase in the volume resistivity is mainly attributed to the prevention of physical contact rather than quantum mechanical effect of electron tunneling via increase in the average distance between the GRP cores. ${ }^{40}$

The most attractive advantage of mechanical coating is the freedom of coating design; the selection of coating material is critical to both TC and EI properties. We coated GRP with various particles to investigate the effect of the types of coating particle on the high volume resistivity of C-GRPs. Fig. 5 shows the SEM images of GRP coated with typical inorganic particles, such as talc (D50: $2 \mu \mathrm{m}$ ), sericite (D50: $2 \mu \mathrm{m}$ ), mica (D50: $5 \mu \mathrm{m}$ ), boemite (D50: $3 \mu \mathrm{m}$ ), BN (D50: $4 \mu \mathrm{m}$ ), titanium dioxide $\left(\mathrm{TiO}_{2}\right)$ (D50: $0.23 \mu \mathrm{m})$, and calcium difluoride $\left(\mathrm{CaF}_{2}\right)(\mathrm{D} 50: 6 \mu \mathrm{m})$. The names of the samples coated with different coating particles are prefixed with C-GRP@, e.g., C-GRP@talc. The volume percentage of the coating particle was fixed at 21 (binder content: $7 \mathrm{vol} \%$ ), which is higher than the threshold value for the highest volume resistivity in Fig. 4. This is because, a thicker shell enhances the breakage stress of the core shell particles. ${ }^{41}$ As shown in the image of C-GRP@talc (Fig. 5(a)), the micronsized talc particles are coated uniformly, similar to the case of CGRP 3 shown in Fig. 1(d). The other minerals such as sericite, mica, and boemite also covered the GRP surface; however, the adhesion of these particles to the surface was insufficient as evident from the surface roughness. Among the particles of simple compositions, the BN particle covered the GRP surface

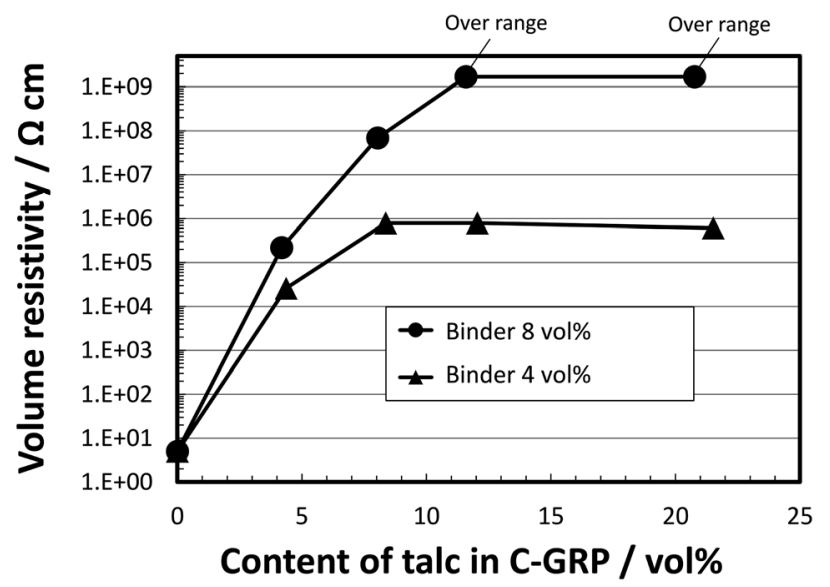

Fig. 4 Volume resistivity of C-GRP prepared by the two-step mixing process as a function of talc content in C-GRP. 

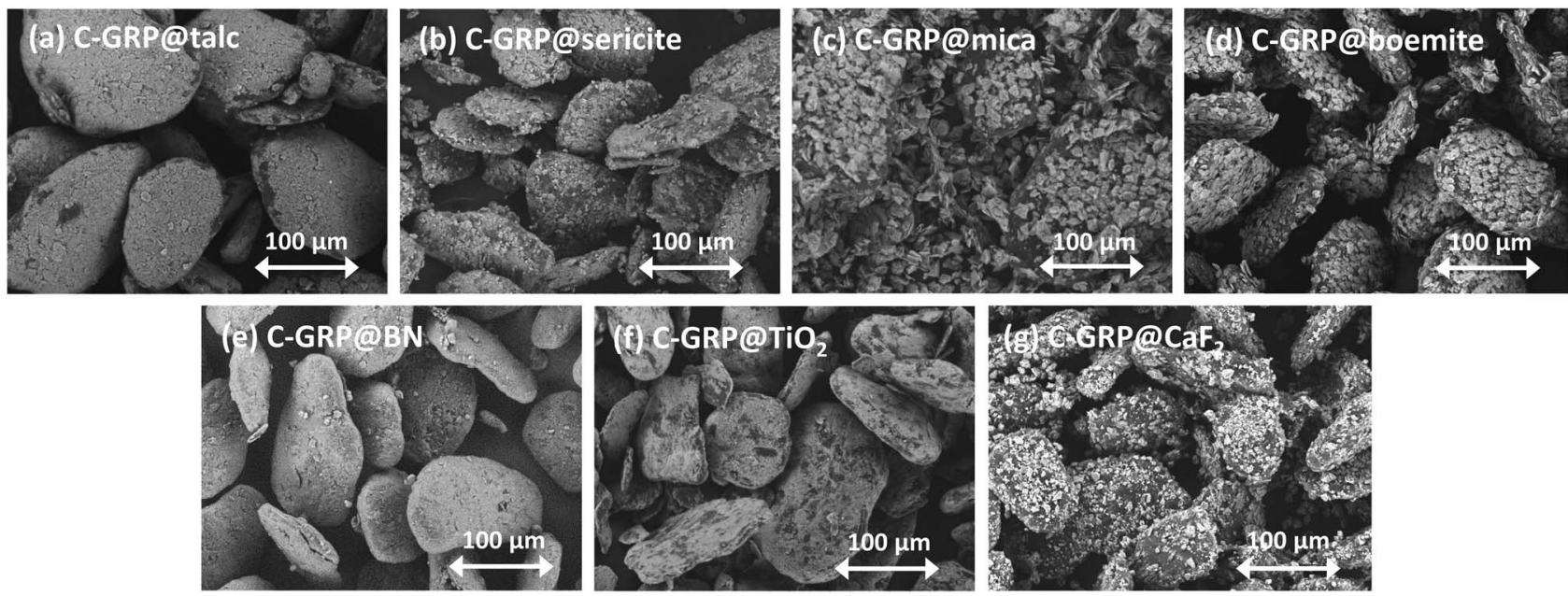

Fig. 5 SEM images of GRP coated with (a) talc, (b) sericite, (c) mica, (d) boemite, (e) $\mathrm{BN}$, (f) $\mathrm{TiO}_{2}$, and (g) CaF 2 particles.

more uniformly compared with $\mathrm{TiO}_{2}$ and $\mathrm{CaF}_{2}$. This difference may be attributed to the affinity difference resulting from the crystal structures of GRP and the coated particle; the two dimensional crystal structure of talc and BN are similar to that of GRP.

Fig. 6 shows the volume resistivity of GRP coated with various particles as compressed forms. C-GRP@talc and CGRP@BN exhibited the highest volume resistivity among all the C-GRPs, greater than approximately $10^{9} \Omega \mathrm{cm}$. Coating with sericite, mica, and boemite also resulted in a relatively high volume resistivity of the corresponding C-GRP, with values greater than $10^{7} \Omega \mathrm{cm}$. On the other hand, C-GRP@TiO ${ }_{2}$ and CGRP@CaF $\mathrm{C}_{2}$ exhibited the lowest volume resistivity, less than $10^{3}$ $\Omega \mathrm{cm}$. The smooth coating surfaces of C-GRP@talc and CGRP@BN are believed to have conduced to the high volume resistivity. The rough coating surfaces of the other C-GRPs possibly caused contact between the GRP cores in their pressed form during evaluation, thereby reducing the volume resistivity. An exception is the behaviour of C-GRP@TiO 2 . The average diameter of $\mathrm{TiO}_{2}$ is only $0.2 \mu \mathrm{m}$ which can contribute to a better coating; however, the volume resistivity of C-GRP@TiO ${ }_{2}$ is less than $10^{3} \Omega \mathrm{cm}$. The round shape of the $\mathrm{TiO}_{2}$ particles

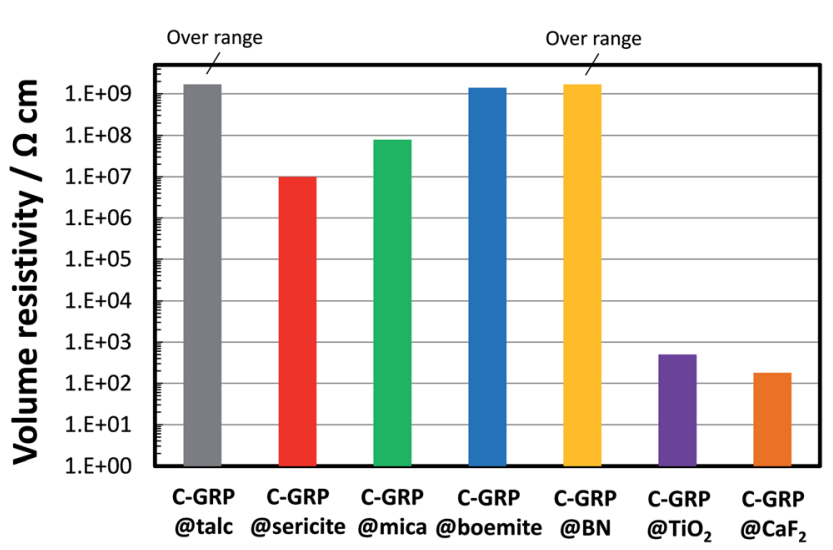

Fig. 6 Volume resistivity of GRP coated with talc, sericite, mica, boemite, $\mathrm{BN}, \mathrm{TiO}_{2}$, and $\mathrm{CaF}_{2}$ particles. appears to be unsuitable for the coating, because of the lesser contact area on the GRP surface when compared with platy particles. These results indicate that a better coating morphology leads to a higher volume resistivity.

The obtained C-GRP samples were compounded with a polyester polymer and moulded into a plate to measure the volume resistivity and the TC. The volume resistivities of the polymer composites were evaluated along the direction of the thickness, because the moulded parts are usually used for electrical safety along this direction. The platy C-GRP is oriented along the in-plane direction during injection moulding; therefore, the surface coverage of the GRP core is critical to achieve a high volume resistivity in terms of possibility of contact. The content of C-GRPs in the composites were fixed at $26 \mathrm{vol} \%$, which is higher than the typical percolation threshold of approximately $11 \mathrm{vol} \%$, for electrical conductivity. ${ }^{42}$ Table 2 shows the volume resistivity of each plate at 100, 250, 500, and $1000 \mathrm{~V}$. The measurements were continued until the volume resistivity was out of range. The moulded plate containing raw GRP exhibited the lowest volume resistivity, $<10^{6} \Omega \mathrm{cm}$ at $100 \mathrm{~V}$. On the other hand, the moulded plates of C-GRP@talc and CGRP@BN exhibited the highest volume resistivity, $>10^{14} \Omega \mathrm{cm}$ at $1000 \mathrm{~V}$. These results indicate that the coating layers of talc and $\mathrm{BN}$ render effective EI even after the melt extrusion and the

Table 2 Volume resistivity of the polymer composites containing CGRPs at different voltages

\begin{tabular}{|c|c|c|c|c|}
\hline & \multicolumn{4}{|c|}{ Volume resistivity $/ \Omega \mathrm{cm}$} \\
\hline & $100 \mathrm{~V}$ & $250 \mathrm{~V}$ & $500 \mathrm{~V}$ & $1000 \mathrm{~V}$ \\
\hline Raw GRP & $<10^{6}$ & - & - & - \\
\hline C-GRP@talc & $>10^{12}$ & $>10^{12}$ & $>10^{13}$ & $>10^{14}$ \\
\hline C-GRP@sericite & $>10^{12}$ & $>10^{12}$ & $<10^{7}$ & - \\
\hline C-GRP@mica & $<10^{6}$ & - & - & - \\
\hline C-GRP@boemite & $>10^{12}$ & $<10^{6}$ & - & - \\
\hline C-GRP@BN & $>10^{12}$ & $>10^{12}$ & $>10^{13}$ & $>10^{14}$ \\
\hline C-GRP@TiO 2 & $<10^{6}$ & - & - & - \\
\hline C-GRP@CaF 2 & $<10^{6}$ & - & - & - \\
\hline
\end{tabular}


moulding processes. In other words, these C-GRP samples exhibit strong shear resistance to retain the particle morphology and its function. The lubrication properties of talc and $\mathrm{BN}$ particles may also contribute to the improved shear resistance of C-GRP compared to the other coating particles. ${ }^{\mathbf{4 3 , 4 4}}$ The force of screws during the melt blending process also support the difference in the lubrication properties (Fig. S2, ESI $\dagger$ ). The plates containing C-GRP@sericite or C-GRP@boemite exhibited moderate volume resistivity compared to that as particles. However, the plate containing C-GRP@mica was electrically conductive in spite of the relatively high volume resistivity of the compressed particle. The mismatch in the volume resistivity of different forms possibly results from delamination of the coating layer during the melt extrusion and the moulding processes. The plates containing C-GRP@TiO or C-GRP@CaF $_{2}$ were electrically conductive even at $100 \mathrm{~V}$, similar to the evaluation results for their compressed particle forms. These results for moulded plates suggest that the concept of coating with electrically insulating particles is effective not only in press moulding but also for melt extrusion and injection moulding processes, depending on the type of the coating particle.

Fig. 7 presents the relation between the TC of the plate containing C-GRPs and the volume resistivity of C-GRPs as particles. The TC properties were measured along the in-plane direction, because the moulded parts are frequently used as an in-plane heat spreader in practical applications. Each TC value was expressed as relative percentage versus the TC value of the plate containing raw GRP. The content of C-GRP was fixed at $26 \mathrm{vol} \%$ in all the polymer composite plates. The TC of the plate containing C-GRP 1 was moderate, because the content of GRP was decreased to 91.3 vol\% in C-GRP 1 . The TC of the methylol melamine binder is less than $0.3 \mathrm{~W} \mathrm{~m}^{-1} \mathrm{~K}^{-1}$; therefore, this could function as a thermal insulator in the particle. The cores of all the C-GRPs were composed of C-GRP 1 and affected by the binder (binder content: 7 vol\% in C-GRPs except for C-GRP 1). Three types of C-GRP@talc (D50 of talc: $0.6 \mu \mathrm{m}$ ) were prepared at various GRP contents, and the TC values of their moulded polymer composite plates were evaluated. The different contents of raw GRP core in C-GRP@talc were 87, 81, and 72 vol\%, with 7 vol\% binder in each case. The TC value of the composite plate

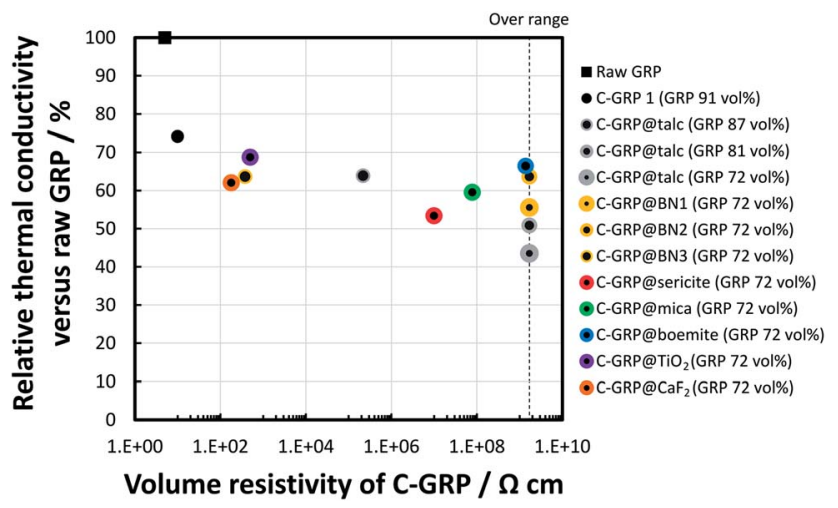

Fig. 7 Relative thermal conductivity of the polymer composites containing C-GRPs at 26 vol\% filler loading versus raw GRP as a function of the volume resistivity of the C-GRPs. gradually decreases by up to $10 \%$ with increase in the volume resistivity by $10^{4} \Omega \mathrm{cm}$. This is attributed to the combined effect of increase in the raw GRP content and prevention of contact between the raw GRP cores. The moulded plate containing CGRP@sericite, C-GRP@mica, and C-GRP@boemite retained their TC values at 53,60, and 66\% respectively. In the cases of $\mathrm{C}$ GRP@TiO ${ }_{2}$ and C-GRP@CaF 2 , the retention percentages of TC value were 69 and $62 \%$, respectively which are relatively high compared to that of others. The trend between the TC value and the volume resistivity indicates the difference in the contact of the GRP core in a polymer composite plate. To investigate the effect of particle diameter on TC of the polymer composites, three types of C-GRP namely, C-GRP@BN1, C-GRP@BN2, and CGRP@BN3 were prepared. The average particle diameter (D50) of BN1, BN2, and BN3 were 4, 8, and $18 \mu \mathrm{m}$, respectively. The retention values of $\mathrm{TC}$ were 55,64 , and $64 \%$, respectively in $\mathrm{C}$ GRP@BN1, C-GRP@BN2, and C-GRP@BN3. Among them, CGRP@BN2 exhibited the highest volume resistivity, greater than $10^{9} \Omega \mathrm{cm}$. On the whole, a weak trade-off relation is observed between the TC and the volume resistivity at the same content of raw GRP. This relation is mainly because of the prevention of GRP contact via a coating layer. This prevention causes a phonon scattering at the coating interface, resulting in a lower TC like in the case of nanocomposites. ${ }^{45}$ On the other hand, the retention of the TC value depends on the type of the coating layer in the range of high volume resistivity, above $10^{9} \Omega \mathrm{cm}$. It is reasonable that the TC difference of the coating layer affects the TC of the moulded plate. Especially, the TC of talc is only $2 \mathrm{~W} \mathrm{~m}^{-1} \mathrm{~K}^{-1}$, whereas that of $\mathrm{BN}$ is approximately $60 \mathrm{~W} \mathrm{~m} \mathrm{~m}^{-1} \mathrm{~K}^{-1}$. This fact indicates that $\mathrm{BN}$ is a more suitable thermal conductor for C-GRP compared with talc.

\section{Conclusions}

We prepared electrically insulating GRPs coated with various particles via an efficient high-shear mixing process. The most promising mixing process comprised a two-step process: mixing of (i) GRPs with a small amount binder as a pre-filler and (ii) pre-filler with various electrically insulating particles. The obtained particles were sufficiently stiff to process the melt extrusion with a polymer. The cross-sectional images of the polymer composites exhibited that the coating layer was retained after the melt extrusion and the injection moulding processes. Especially, C-GRP@talc and C-GRP@BN exhibited a high volume resistivity, both in the form of compressed particles and polymer composites. The polymer composites had a weak tendency to show lower TC values at higher volume resistivity of C-GRP. The two-step synthesis process of C-GRP can be extended to the fabrication of unique hybrid fillers for melt extrusion with polymers. The obtained C-GRP is useful for thermally conductive and electrically insulating polymer composites for injection moulding.

\section{Conflicts of interest}

There are no conflicts to declare. 


\section{Acknowledgements}

This work was partially supported by New Energy and Industrial Technology Development Organization (NEDO) based on the strategic program for innovative energy efficiency technology, 14102124-0.

\section{Notes and references}

1 C. P. Wong and R. S. Bollampally, J. Appl. Polym. Sci., 1999, 74, 3396.

2 E. M. C. Wong, IEEE Transactions on Consumer Electronics, 1994, 40, 28.

3 S. P. Gurrum, D. R. Edwards, T. Marchand-Golder, J. Akiyama, S. Yokoya, J.-F. Drouard and F. Dahan, IEEE 62nd Electron. Compon. Technol. Conf., 2012, p. 1488.

4 N. Saba, P. M. Tahir and M. Jawaid, Polymers, 2014, 6, 2247. 5 H. Chen, V. V. Ginzburg, J. Yang, Y. Yang, W. Liu, Y. Huang, L. Du and B. Chen, Prog. Polym. Sci., 2016, 59, 41.

6 Y. V. Trofimov, S. I. Lishik and P. P. Pershukevich, Semicond. Phys., Quantum Electron. Optoelectron., 2013, 16, 198.

7 M.-H. Chang, D. Das, P. V. Varde and M. Pecht, Microelectron. Reliab., 2012, 52, 762.

8 X. Perpinñà, R. J. Werkhoven, M. Vellvehi, J. Jakovenko, X. Jordà, J. M. G. Kunen, P. Bancken and P. J. Bolt, IEEE Xplore: IEEE Transactions on Power Electronics, 2015, 30, 3876.

9 I. Pleşa, P. V. Noţingher, S. Schlögl, C. Sumereder and M. Muhr, Polymers, 2016, 8, 173.

10 M. A. Vadivelu, C. R. Kumar and G. M. Joshi, Compos. Interfaces, 2016, 23, 847.

11 S. M. Lebedev and O. S. Gefle, Appl. Therm. Eng., 2015, 91, 875.

12 C. Feng, H. Ni, J. Chen and W. Yang, ACS Appl. Mater. Interfaces, 2016, 8, 19732.

13 M. Shtein, R. Nadiv, M. Buzaglo, K. Kahil and O. Regev, Chem. Mater., 2015, 27, 2100.

14 S. Zhang, X. Y. Cao, Y. M. Ma, Y. C. Ke, J. K. Zhang and F. S. Wang, eXPRESS Polym. Lett., 2011, 5, 581.

15 A. A. Wereszczak, T. G. Morrissey, C. N. Volante, P. J. Farris Jr., R. J. Groele, R. H. Wiles and H. Wang, IEEE Trans. Compon., Packag., Manuf. Technol., 2013, 3, 1994.

16 C. Yuan, B. Duan, L. Li, B. Xie, M. Huang and X. Luo, ACS Appl. Mater. Interfaces, 2015, 7, 13000.

17 Z. Lin, A. Mcnamara, Y. Liu, K.-S. Moon and C.-P. Wong, Compos. Sci. Technol., 2014, 90, 123.

18 J. Li, M. Nakamura, T. Shirai, K. Matsumaru, C. Ishizki and K. Ishizaki, J. Am. Ceram. Soc., 2006, 89, 937.

19 G. P. Akishin, S. K. Turnaev, V. Y. Vaispapir, M. A. Gorbunova, Y. N. Makurin, V. S. Kiiko and A. L. Ivanovskii, Refract. Ind. Ceram., 2009, 50, 465.
20 X. Cai, Z. Jiang, X. Zhang, T. Gao, K. Yue and X. Zhang, RSC $A d v ., 2018$, 8, 11367.

21 J. Gu, C. Liang, X. Zhao, B. Gan, H. Qiu, Y. Guo, X. Yang, Q. Zhang and D.-Y. Wang, Compos. Sci. Technol., 2017, 139, 83.

22 A. K. Pandey, R. Kumar, V. S. Kachhavah and K. K. Kar, $R S C$ $A d v .$, 2016, 6, 50559.

23 D. Kim, S. Ha, H. K. Choi, J. Yu and Y. A. Kim, RSC Adv., 2018, 8, 4426.

24 X. Yang, L. Tang, Y. Guo, C. Liang, Q. Zhang, K. Kou and J. Gu, Composites, Part A, 2017, 101, 237.

25 T. Morishita and N. Takahashi, RSC Adv., 2017, 7, 36450.

26 R. Qian, J. Yu, C. Wu, X. Zhai and P. Jiang, RSC Adv., 2013, 3, 17373.

27 X. Pu, H.-B. Zhang, X. Li, C. Gui and Z.-Z. Yu, RSC Adv., 2014, 4, 15297.

28 D. Tang, J. S. Q. Yang, M. Kong, Z. Zhao, Y. Huang, X. Liao and Y. Liu, RSC Adv., 2015, 5, 55170.

29 S. Choi, Y. Kim, J. H. Yun, I. Kim and S. E. Shim, Mater. Lett., 2013, 90, 87.

30 S. Choi, K. Kim, J. Nam and S. E. Shim, Carbon, 2013, 60, 254.

31 Y. Kim, Y. Qian, M. Kim, J. Ju, S.-H. Baeck and S. E. Shim, RSC Adv., 2017, 7, 24242.

32 Y. Noma, Y. Saga and N. Une, Carbon, 2014, 78, 204.

33 M. Alonso, M. Satoh and K. Miyanami, Powder Technol., 1989, 59, 45.

34 R. Pfeffer, R. N. Dave, D. Wei and M. Ramlakhan, Powder Technol., 2001, 117, 40.

35 C.-S. Chou, R.-Y. Yang, M.-H. Weng and C.-H. Yeh, Powder Technol., 2008, 187, 181.

36 A. Mujumdar, D. Wei, R. N. Dave, R. Pfeffer and C.-Y. Wu, Powder Technol., 2004, 140, 86.

37 A. E. D. Rio-Castillo, C. Merino, E. Díez-Barra and E. Vázquez, Nano Res., 2014, 7, 963.

38 M. Yi and Z. Shen, J. Mater. Chem. A, 2015, 3, 11700.

39 M. Weber, A. Spettl, M. Dosta, S. Heinrich and V. Schmidt, Comput. Mater. Sci., 2017, 137, 100.

40 J.-F. Zou, Z.-Z. Yu, Y.-X. Pan, X.-P. Fang and Y.-C. Ou, J. Polym. Sci., Part B: Polym. Phys., 2002, 40, 954.

41 M. O'Sullivan, Z. Zhang and B. Vincent, Langmuir, 2009, 25, 7962.

42 I. Krupa, I. Novák and I. Chodák, Synth. Met., 2004, 145, 245.

43 J. K. Katiyar, S. K. Sinha and A. Kumar, Wear, 2016, 362-363, 199.

44 Y. Kimura, T. Wakabayashi, K. Okada, T. Wada and H. Nishikawa, Wear, 1999, 232, 199.

45 W. Tian and R. Yang, Computer Modeling in Engineering and Sciences, 2008, 24, 123. 